\title{
Laryngeal dysfunction and the pulmonary syndrome of the newborn
}

\author{
G. R. OSBORN AND R. L. FLETT \\ From the Departments of Pathology and Otorhinolaryngology, Derbyshire Royal Infirmary
}

SYNOPSIS 'The pulmonary syndrome of the newborn' is a term used for a complex group of lesions. It has been found that in the important forms of this disorder lesions of the larynx are very common, probably constant, and are ulcers of pressure type occurring on the vocal folds and ventricular bands ('true' and 'false' cords). Abnormal closure of the larynx, especially spasm, must be the cause of the ulceration. Premature babies may breathe with alveolar ducts and with alveoli in different parts of the same lung. It is suggested that hyaline membrane forms because of the abuse of normal alveolar duct function in alveolar duct type respiration. Membrane formation is a secondary phenomenon. The lesions of the pulmonary syndrome of the newborn based on a correlation of laryngeal and pulmonary function are classified, and the correlation of function suggests that early treatment with an artificial larynx might prevent the development of the fatal lesions.

Valvular mechanisms in the lungs responsible for obstructive emphysema and obstructive atelectasis have been described by Jackson and Jackson (1945) and by Osborn (1953). In the newborn the ball-valve type of obstruction appears to be the most significant (Fig. 1), but it has become clear that in an important group of cases no adequate demonstrable explanation can be found in the trachea and lungs. In these babies lesions are found in the larynx within a very short time of birth which enable us to understand the lung findings.

Negus $(1929,1949)$ showed that the larynx was not evolved for speech but is a valve designed to keep water and other foreign substances out of the lungs; it is also necessary for fixation of the thorax, especially in arboreal animals (Figs. 2, 3, and 4). The most primitive form of larynx is muscular only but as it cannot withstand a water pressure of more than $4 \mathrm{~mm}$. of mercury it is inefficient and higher animals have developed valves. Shaping the larynx like an inverted V (or Gothic arch) will cause it to close more tightly as pressure increases. The human larynx has two valves of this type. The lower is the subglottic region and the vocal folds. The upper, and the more important for the exclusion of water, is formed by the aryepiglottic folds which are in fact inlet valves. Between the two inlet valves there is a more efficient outlet valve, the ventricular bands or false cords. For running, the larynx reaches its Received for publication 14 April 1962. highest evolutionary stage in the horse and deer; for an arboreal existence, in lemurs and some monkeys. Because the human larynx is a regressive organ from the evolutionary viewpoint, we might expect it to be more efficient in the newborn than in later life. The newborn prove its efficiency by their ability to support their weight by holding with their hands, and by their ability to breathe and drink at the same time-a feat which would be dangerous if possible in later life (Negus, 1961). The efficiency of the ventricular bands as outlet valves depends to a large extent on the saccules which are better developed at birth than in children and adults (Fig. 8).

If the foetus is partially asphyxiated before birth the larynx nearly always fails in its function of keeping everything except air out of the lungs (Fig. 5). Liquor amnii, blood, pus, mucus, nucleated and non-nucleated squames can all pass both the aryepiglottic and the vocal folds. Unlike a drowning person a foetus may obtain some oxygen through the umbilical cord and so be about half asphyxiated for a considerable period of time while it both inhales and swallows the content of the upper air passages (Osborn, 1958). If the newborn baby is to inhale air properly it is obvious that mucus, squames, and so on should not be ahead of the first breath. The air inhaled with the first breath will only go as far as the alveolar ducts; to expand the alveoli it must be expired against resistance; while being forced out it will also be forced backwards into the alveoli (Negus, 


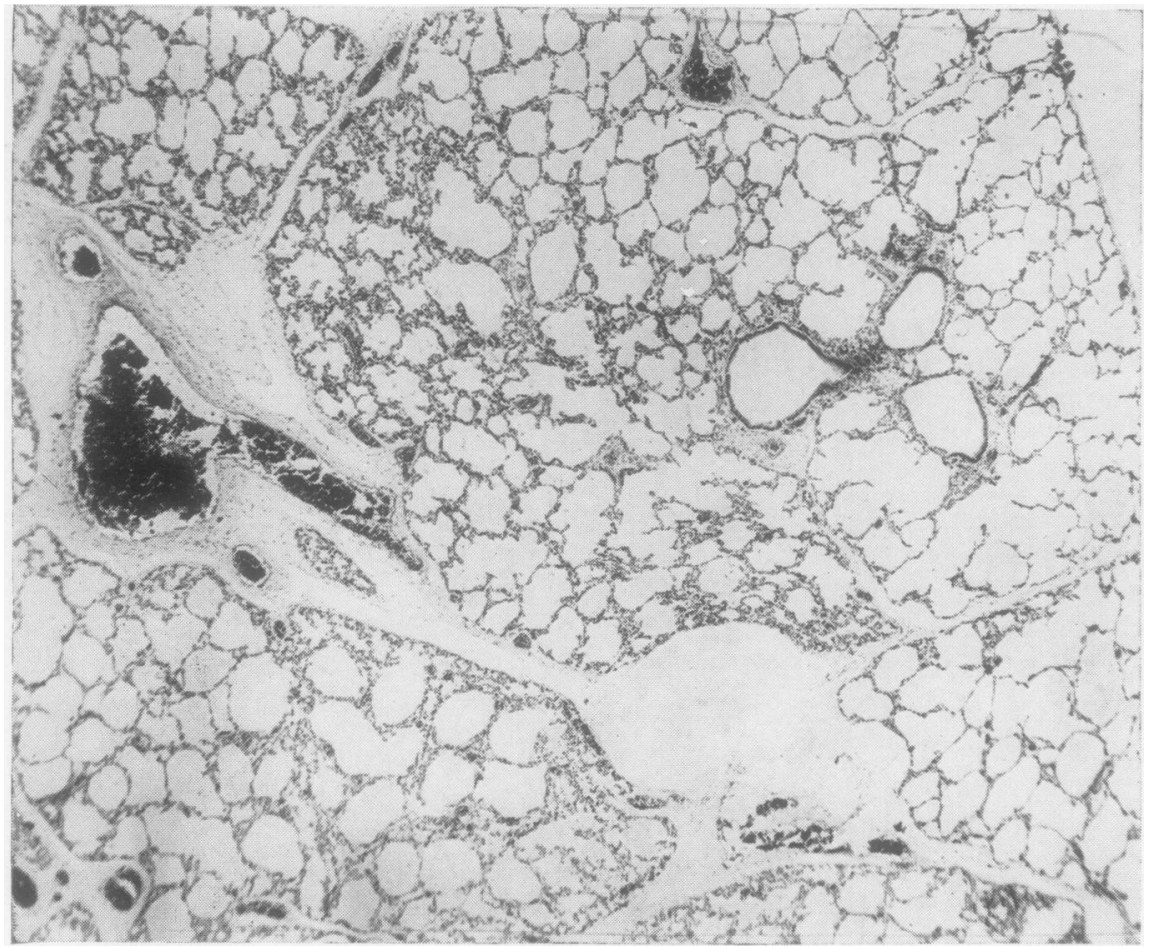

FIG. 1. Lungs of $a$

baby dying at birth

from obstructive

emphysema caused by

tenacious mucus in the

trachea which acted as a

ball valve allowing air

into the lungs but

preventing its return

through the glottis.

So few breaths were

taken that the

obstetrician thought this

might be a stillbirth.

$\times 20$.
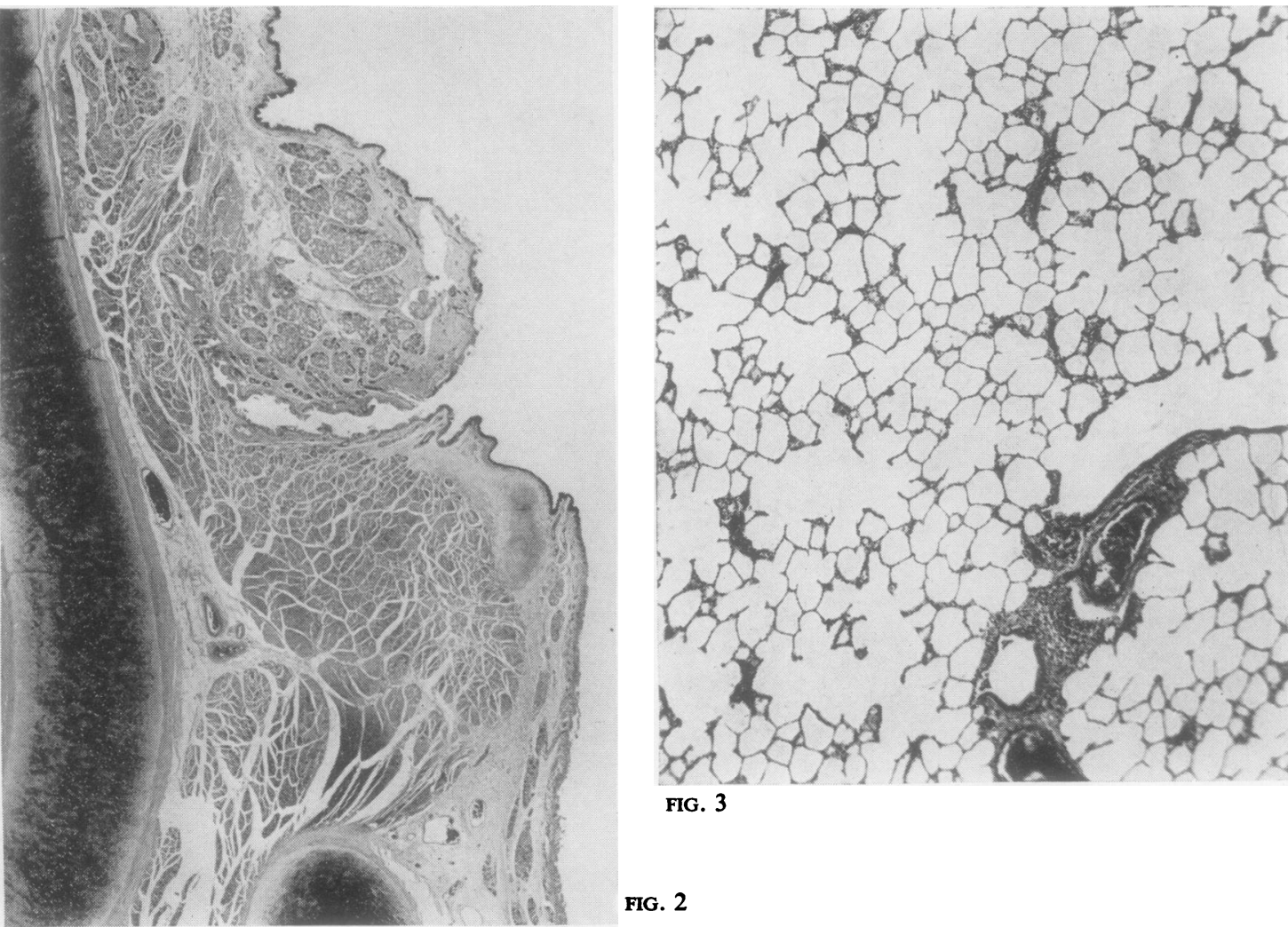

FIG. 3

FIG. 2 




FIG. 4

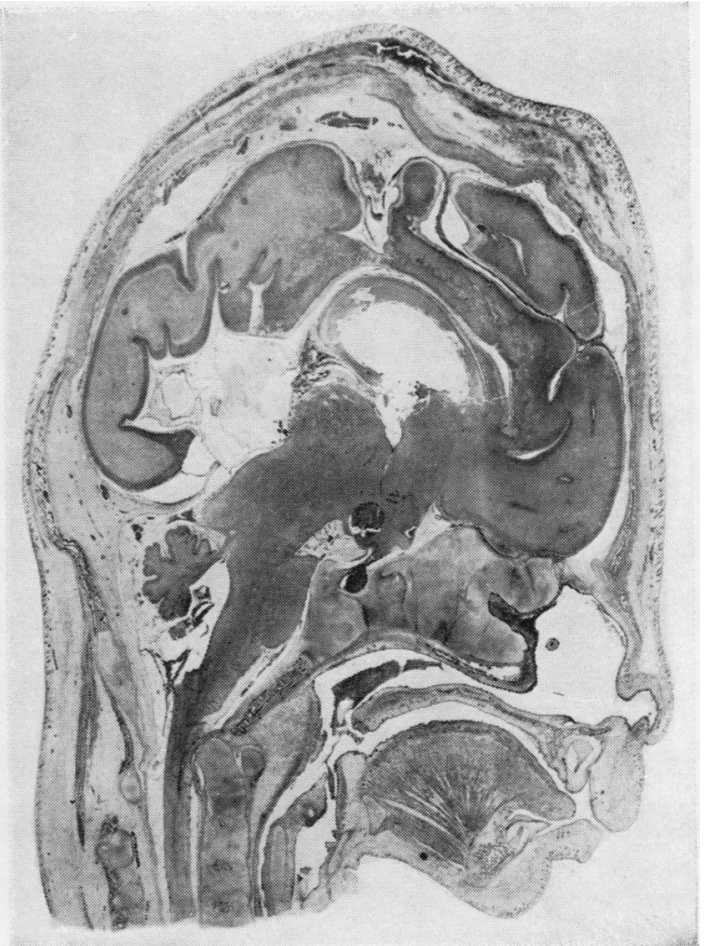

FIG. 5

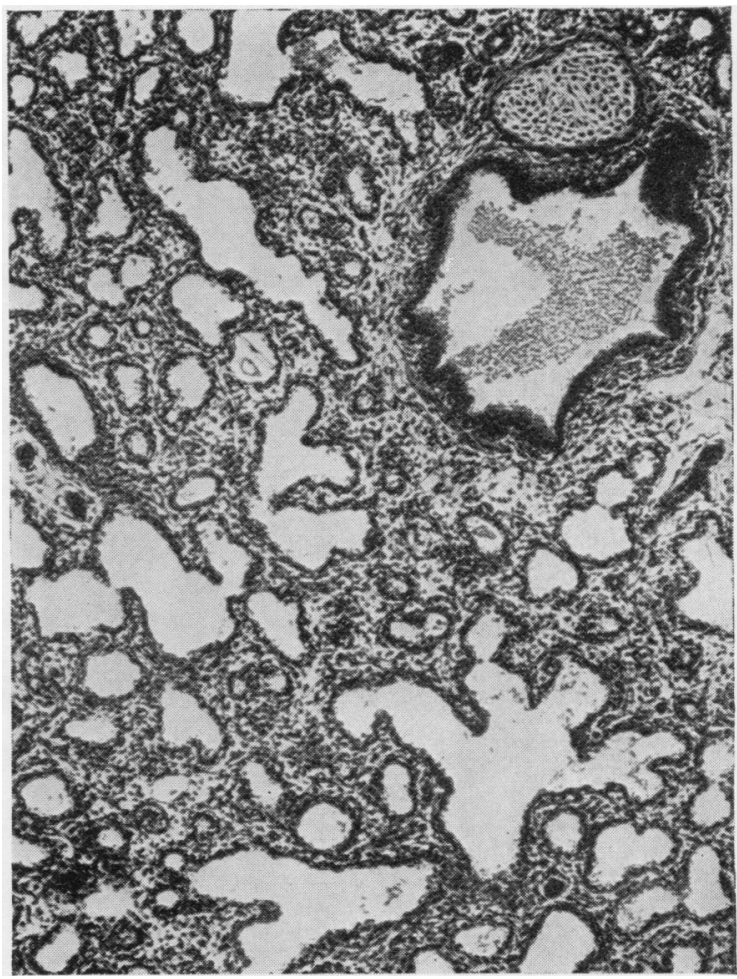

FIG. 6
FIG. 2. Section from larynx of a boy of 7 years who was drowned. The superior fold (ventricular band or false cord), aided by the ventricle extending cranio-laterally, is an outlet valve and hinders or prevents escape of air from the lungs. The inferior fold (vocal cord) is the lower of the two inlet valves, and helps to prevent water entering the lungs, but its main function is hindering entry of air to permit fixation of the thorax in arboreal and other animals. The strong sphincter muscle can be seen in the inferior fold; the superior fold contains glands rather than muscle fibres. $\times 15$.

FIG. 3. Obstructive emphysema ('emphysema aquosum') in the lungs of the 7-year-old boy whose larynx is shown in Figure 2. $\times 20$.

FIG. 4. Lungs of a newborn baby thought to have been drowned as a result of being thrown into the sea. Obstructive emphysema present. (Case of Dr. E. G. Evans of Bangor.) $\times 20$.

FIG. 5. Head of a foetus of about 25 weeks' development. The dark collection of pus above the hard and soft palate is seen passing directly through the larynx into the trachea. This 'drowning in pus' is one of the forms of 'congenital pneumonia'. $\times 5$.

FIG. 6. Lungs of a $27 \mathrm{~cm}$. foetus (about 25 weeks) showing alveolar duct type respiration. The alveoli have not differentiated, hence although such a foetus may breathe air for a short time it is not viable. $\times 20$. 


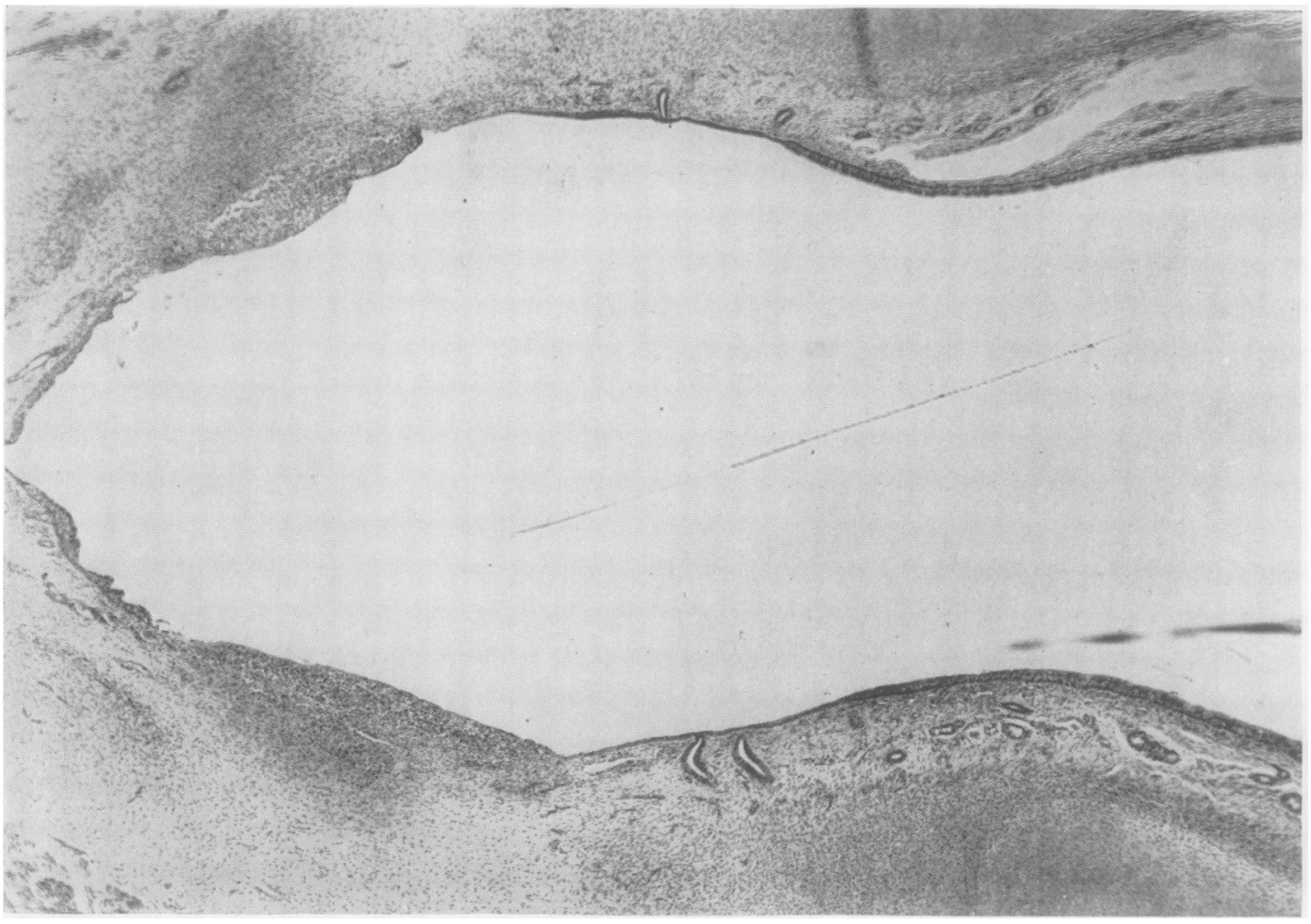

FIG. 7

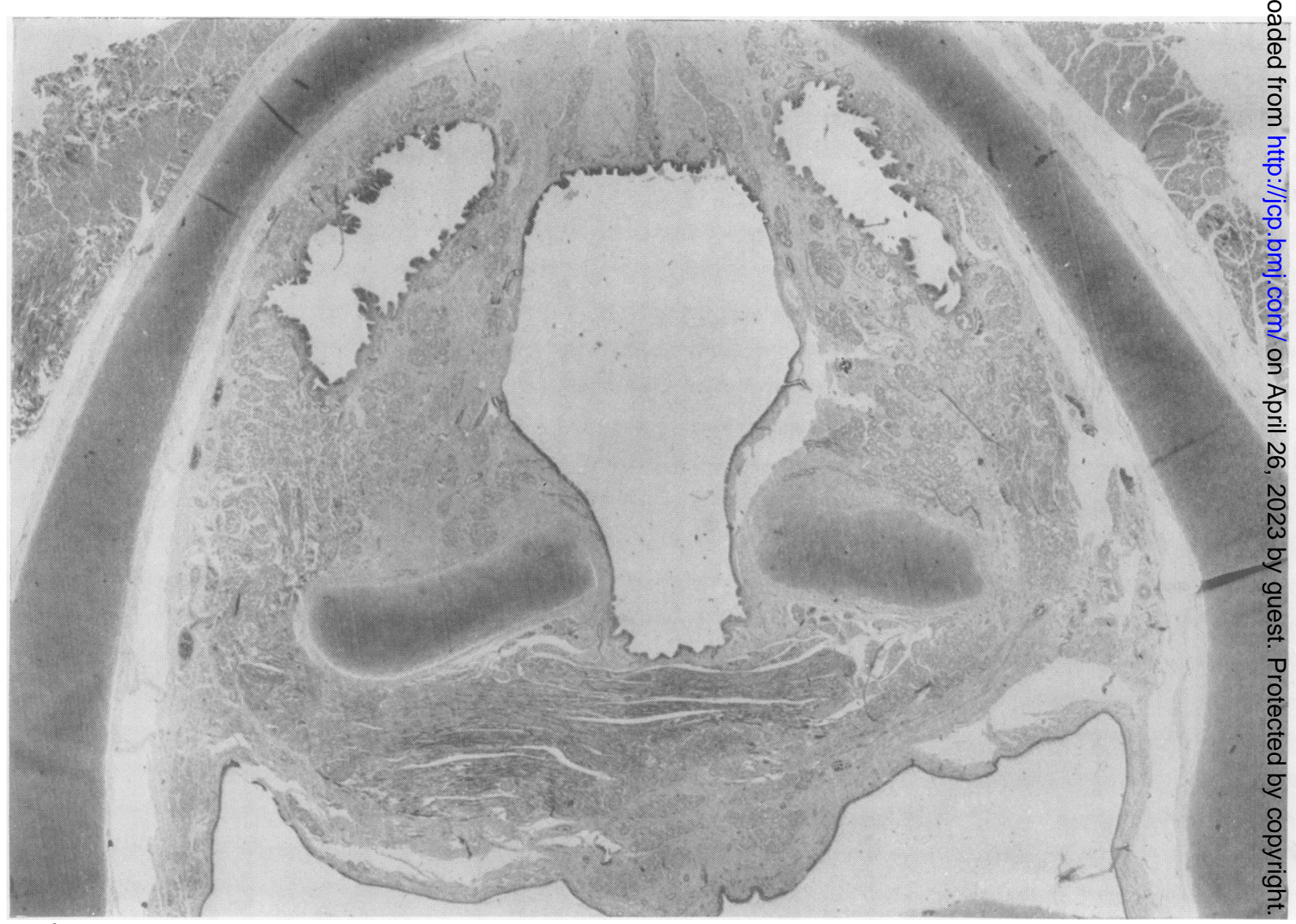

FIG. 8 
FIG. 7. Ulceration of both vocal folds (cords) with a heavy inflammatory exudate in a baby dying of bronchopneumonia at the age of 1 day. Note the normal surface epithelium a short distance from the ulcers, the flattened epithelium close to the ulcers and its gradual disappearance at the ulcer edge. This is characteristic of ulcers due to pressure. $\times 30$.

FIG. 8. Same case as in Figure 7 to show ulceration of the ventricular bands (false cords). The histological features of ulceration following pressure atrophy of the epithelium are again well shown. There is very little inflammatory exudate. The saccules of the ventricles are shown anteriorly on either side and help to make the ventricular bands more efficient as exit valves at birth as compared with later in life. $\times 11$.

FIG. 9. Lungs of the baby whose larynx is shown in Figs. 7 and 8.

Bronchopneumonic consolidation is present but most of the lungs is emphysematous. $\times 20$.

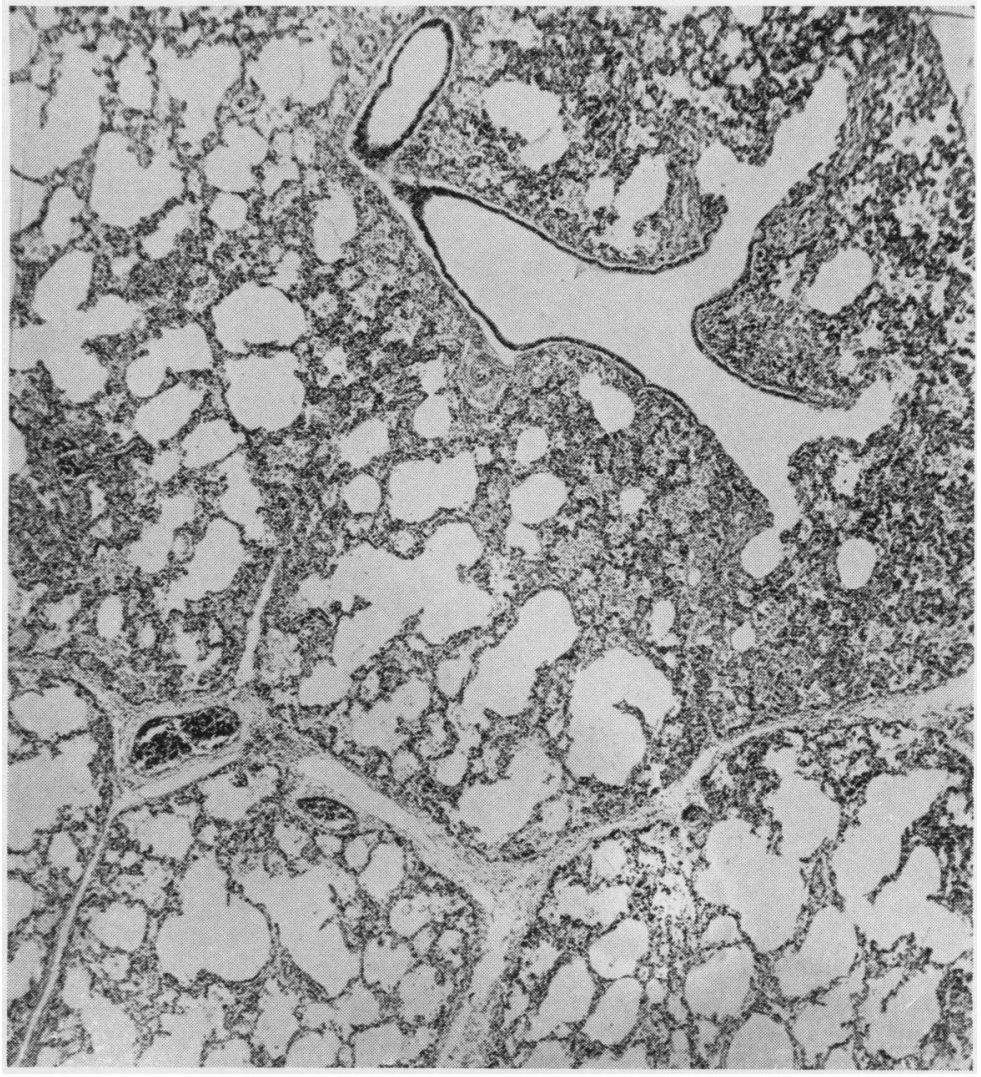

FIG. 9
1929, and Fig. 24). Crying appears to be an important means of forcing air out and backwards under pressure.

The alveolar ducts and alveoli have very little mechanical strength. Negus (1929) has shown experimentally that in a system like this, if there is a wide opening to the outside air, only the nearer of the weak-walled elements will expand and contract as air goes in and out, implying that if the normal valvular action of the larynx fails at birth the alveolar ducts will balloon, the alveoli will not expand, and the condition of hyaline membrane will follow.

The stimulus to breathe is seen early in foetal development. Respiratory efforts are functionally quite useless until the alveolar ducts have differentiated at between 20 and 24 weeks' development. Alveolar duct respiration has been observed to keep a foetus of about 25 weeks' development alive in the laboratory for an hour (Fig. 6). A foetus is not viable until its alveoli have differentiated sufficiently to be of functional use. In the transitional stage, between alveolar respiration being impossible, up to about 28 weeks, and easy at full term, the premature baby may begin either the alveolar duct or the alveolar type of respiration. There is little doubt that in favourable cases the former can be replaced by the latter; also that in some babies both types of respiration occur, the alveolar duct type being more likely near the hilus and posteriorly. Ballooning of the alveolar ducts can cause the lungs to fill the chest cavity; if this happens it is improbable that any form of treatment will change alveolar duct into alveolar type respiration. Although complete failure of laryngeal function at birth cannot be demonstrated by the pathologist, it must be postulated that it does occur in some babies, and it has in fact been observed by Jackson (1915) and by Professor H. C. McLaren (1961). The lesions resulting from the opposite condition of laryngeal spasm can be demonstrated histologically.

\section{THE LARYNGEAL LESIONS}

The sequence of lesions in the larynx, thought to result from spasm, is the same as in the oesophagus, trachea, and urethra when a tube or catheter is left 
in contact with the mucosa (Osborn, 1958). The part typically affected is the junction of the anterior and middle thirds of the vocal folds, that is, the middle of the mobile part of the vocal cord (Figs. 7, 10, 18, 21 , and 22), and is the part affected by 'singer's nodes' in later life. In the newborn the synonym 'screamer's nodes' is more appropriate (Fig. 15). The analogy is one of position and not of histological structure.

The first stage is pressure atrophy (flattening) of the stratified squamous epithelium of the vocal fold; the epithelium then disappears but the resulting ulcer has compressed epithelium at its edges. In the second stage an inflammatory exudate, in which polymorphonuclear leucocytes predominate, develops and is a leucotaxine type of response due to the products of epithelial breakdown. Local haemorrhage may occur but it is usually slight or absent. Haemorrhage is frequent between the vocal cord and the anterior part of the thyro-arytenoid muscle (Fig. 10); it is not uncommon in the foetus and should be considered asphyxial in origin. In the third stage the inflammatory exudate increases, and the inflammation spreads into the ventricle and to the ventricular bands ('false cords') (Fig. 8). The lesion of the ventricular band is similar to that of the vocal fold but usually less severe; this difference is probably structural in origin. The vocal fold is a valve with a strong sphincter muscle (Figs. 2 and 18) and the ventricular band a valve with many glands and few muscle fibres. The inflammation has not been observed to extend towards the subglottic region. Finally bacteria lodge on the ulcerated parts. The lesions of the vocal folds and ventricular bands are not primarily bacterial in origin and infection is typically late, a fact of importance in the management of the newborn child with laryngeal ulceration.

\section{PATHOGENESIS OF LARYNGEAL ULCERATION}

Because the pathological lesions seen in the vocal folds and ventricular bands are so very similar to those in the oesophagus and urethra caused by an indwelling tube, it was at first concluded that the aetiology was the same, and the obvious explanation was damage to the larynx by a mucus catheter. A study of the distance from the lips to the aryepiglottic folds was therefore made at necropsy in babies of various weights as it was thought that these measurements would enable the mucus catheter to be calibrated and so used more safely. Typical distances were found to be $2.5 \mathrm{~cm}$. in a 15-day female weighing $1 \mathrm{lb} .6 \mathrm{oz}$; $4 \mathrm{~cm}$. in a male of 10 hours weighing $1 \mathrm{lb}$. $14 \mathrm{oz}$; $5 \mathrm{~cm}$. in a stillborn female weighing $4 \mathrm{lb} .6 \mathrm{oz}$; and $4.5 \mathrm{~cm}$. in a stillborn female weighing $6 \mathrm{lb} .12 \mathrm{oz}$. It is, however, very difficult to be sure that this distance as measured at necropsy represents the distance during life with any degree of accuracy. Reliable case histories soon made it clear that this conclusion was untenable. Some of the babies had not had a mucus catheter passed nor did there appear to be any possibility of mechanical damage to the larynx by the attendant. The only tenable conclusion was that the damage resulted from the vocal folds being too tightly apposed in their spasm. There is, however, one other possibility which may be a factor in a few cases.

Jackson and Jackson (1937) wrote: 'Untold thousands of infants have asphyxiated because of bilateral abductor paralysis - the cyanosis being attributed to a persistent foramen ovale or failure of respiration to start'. Cavanagh (1955) has described vocal palsies in children. She had to perform 11 tracheostomies on babies between the ages of a few days and 5 months because of vocal cord palsy and five of these died. She considers the first six months of life the period of greatest hazard. Because there was no obvious central cause of laryngeal paralysis in the present series of babies, the recurrent laryngeal nerves were studied histologically. The recurrent nerves appeared normal, and abnormalities, when present, took the form of small asphyxial haemorrhages which did not appear to be causing pressure on the nerve fibres; these can have no clinical significance. Practically all the births were easy and natural so difficult labour was not the cause.

\section{LUNG LESIONS IN BABIES WITH ULCERATED VOCAL FOLDS}

It was thought desirable to look at the problem from two different angles. First, what are the lung lesions found in the presence of ulcerated vocal folds? Secondly, is there any lung condition which is not found in the absence of ulcerated vocal folds?

The lung lesions in the 32 babies with ulcerated vocal folds are set out briefly in Table I. They are placed in four main groups but the dividing line between the groups is not clear in some cases.

The first group of babies numbers eight and are diagnosed as cases of bronchopneumonia. Case 8 had an operation for volvulus resulting from fibrocystic disease of the pancreas. Case 4, the only baby with normal vocal cords, had an operation for exomphalos when an intratracheal tube passed for anaesthesia damaged the posterior part of the larynx. Case 5 had an $E$. coli meningitis and umbilical cord sepsis. Cases 6 and 7 had an infection of the vocal folds and other parts with Candida albicans. Case 2 is clearly a case of 'hyaline membrane without membrane' (Figs. 10 and 11). The important lesions are well shown in Case 1 (Figs. 7, 8, and 9). 
TABLE I

LUNG FINDINGS IN 32 BABIES WITH LARYNGEAL ULCERATION

\begin{tabular}{|c|c|c|c|c|c|c|c|c|c|c|}
\hline $\begin{array}{l}\text { Case } \\
\text { No. }\end{array}$ & Sex & Age & $\begin{array}{l}\text { Weight } \\
(g .)\end{array}$ & $\begin{array}{l}\text { Broncho- } \\
\text { pneumonia }\end{array}$ & $\begin{array}{l}\text { Asphyxial } \\
\text { Haemor- } \\
\text { rhages }\end{array}$ & Oedema & $\begin{array}{l}\text { Alveolar } \\
\text { Duct } \\
\text { Ballooning }\end{array}$ & Atelectasis & Emphysema & Other Notes \\
\hline \multicolumn{11}{|c|}{ Bronchopneumonia } \\
\hline $\begin{array}{l}1 \\
2\end{array}$ & $\begin{array}{l}\mathbf{F} \\
\mathbf{M}\end{array}$ & $\begin{array}{l}1 \text { day } \\
28 \mathrm{hr} \text {. }\end{array}$ & $\begin{array}{l}2,548 \\
1,428\end{array}$ & $\begin{array}{l}+t+ \\
+\end{array}$ & $\begin{array}{l}++ \\
+\end{array}$ & + & $\vec{t}+$ & $\bar{t}+$ & $\begin{array}{l}++ \\
-\end{array}$ & $\begin{array}{l}\text { Hyaline membrane with- } \\
\text { out membrane }\end{array}$ \\
\hline $\begin{array}{l}3 \\
4 \\
5 \\
6 \\
7 \\
8\end{array}$ & $\begin{array}{l}\mathbf{M} \\
\mathbf{M} \\
\mathbf{F} \\
\mathbf{F} \\
\mathbf{M} \\
\mathbf{M}\end{array}$ & $\begin{array}{l}30 \mathrm{hr} . \\
30 \mathrm{hr} . \\
3 \text { days } \\
5 \text { days } \\
12 \text { days } \\
3 \text { wk. }\end{array}$ & $\begin{array}{l}1,372 \\
2,520 \\
2,828 \\
1,120 \\
2,380 \\
2,296\end{array}$ & $\begin{array}{l}++ \\
+ \\
+++ \\
++ \\
+++ \\
+++\end{array}$ & $\begin{array}{l}t+ \\
+ \\
+ \\
++t \\
- \\
+\end{array}$ & $\begin{array}{l}- \\
- \\
+ \\
+\end{array}$ & $\begin{array}{l}- \\
- \\
+ \\
+ \\
-\end{array}$ & $\begin{array}{l}- \\
++ \\
- \\
- \\
- \\
-\end{array}$ & $\begin{array}{l}+t \\
+ \\
++ \\
+ \\
++ \\
++t\end{array}$ & $\begin{array}{l}\text { Exomphalos } \\
\text { B. coli meningitis } \\
\text { Candida albicans } \\
\text { Candida albicans } \\
\text { Fibrocystic disease }\end{array}$ \\
\hline \multicolumn{11}{|c|}{ Hyaline Membrane } \\
\hline $\begin{array}{r}1 \\
2 \\
3 \\
4 \\
5 \\
6 \\
7 \\
8 \\
9 \\
10 \\
11 \\
12 \\
13\end{array}$ & $\begin{array}{l}\mathbf{M} \\
\mathbf{M} \\
\mathbf{M} \\
\mathbf{F} \\
\mathbf{F} \\
\mathbf{F} \\
\mathbf{M} \\
\mathbf{M} \\
\mathbf{F} \\
\mathbf{F} \\
\mathbf{M} \\
\mathbf{M} \\
\mathbf{M}\end{array}$ & $\begin{array}{l}6 \mathrm{hr} \text {. } \\
15 \mathrm{hr} \text {. } \\
17 \mathrm{hr} \text {. } \\
30 \mathrm{hr} \text {. } \\
33 \mathrm{hr} \text {. } \\
34 \mathrm{hr} \text {. } \\
36 \mathrm{hr} \text {. } \\
42 \mathrm{hr} \text {. } \\
44 \mathrm{hr} \text {. } \\
44 \mathrm{hr} \text {. } \\
46 \mathrm{hr} . \\
47 \mathrm{hr} \text {. } \\
2 \mathrm{days}\end{array}$ & $\begin{array}{l}2,040 \\
2,240 \\
1,652 \\
1,480 \\
2,040 \\
1,876 \\
1,652 \\
1,848 \\
1,680 \\
1,288 \\
1,708 \\
2,464 \\
1,848\end{array}$ & $\begin{array}{l}- \\
- \\
- \\
- \\
- \\
- \\
- \\
- \\
+ \\
+ \\
- \\
+ \\
-\end{array}$ & $\begin{array}{l}+ \\
++ \\
++ \\
+ \\
+ \\
++ \\
+ \\
+ \\
+++ \\
+ \\
+ \\
+ \\
+++\end{array}$ & $\begin{array}{l}++ \\
+ \\
+ \\
- \\
+ \\
- \\
- \\
+- \\
+ \\
- \\
+ \\
+-+ \\
-\end{array}$ & $\begin{array}{l}++ \\
+++ \\
+++ \\
+++ \\
+++ \\
+++ \\
+++ \\
+++ \\
++ \\
+++ \\
+++ \\
++ \\
++\end{array}$ & $\begin{array}{l}++ \\
++ \\
+++ \\
+++ \\
+++ \\
+++ \\
++ \\
+++ \\
++ \\
++ \\
++ \\
++ \\
++\end{array}$ & $\begin{array}{l}+ \\
+ \\
- \\
\overline{+} \\
\overline{+} \\
+ \\
+ \\
+ \\
+ \\
+ \\
+\end{array}$ & Caesarian syndrome \\
\hline \multicolumn{11}{|c|}{ Emphysema } \\
\hline $\begin{array}{l}1 \\
2 \\
3 \\
4\end{array}$ & $\begin{array}{l}\mathbf{F} \\
\mathbf{M} \\
\mathbf{M} \\
\mathbf{M}\end{array}$ & $\begin{array}{l}3 \text { hr. } \\
2 \text { days } \\
3 \text { days } \\
3 \text { days }\end{array}$ & $\begin{array}{l}1,316 \\
3,220 \\
2,408 \\
2,108\end{array}$ & $\begin{array}{l}- \\
- \\
- \\
-\end{array}$ & $\begin{array}{l}++ \\
++ \\
+ \\
+\end{array}$ & $\begin{array}{l}++ \\
+ \\
- \\
-\end{array}$ & $\begin{array}{l}- \\
- \\
-\end{array}$ & $\begin{array}{l}- \\
- \\
-\end{array}$ & $\begin{array}{l}+ \\
+++ \\
+++ \\
++\end{array}$ & \\
\hline \multicolumn{11}{|c|}{ Interstitial Emphysema and Pneumothorax } \\
\hline $\begin{array}{l}1 \\
2 \\
3 \\
4 \\
5 \\
6 \\
7\end{array}$ & $\begin{array}{l}\mathbf{F} \\
\mathbf{F} \\
\mathbf{M} \\
\mathbf{F} \\
\mathbf{M} \\
\mathbf{F} \\
\mathbf{M}\end{array}$ & $\begin{array}{l}3 \mathrm{hr} . \\
6 \mathrm{hr} . \\
10 \mathrm{hr} . \\
13 \mathrm{hr} . \\
20 \mathrm{hr} . \\
53 \mathrm{hr} . \\
58 \mathrm{hr} \text {. }\end{array}$ & $\begin{array}{r}2,856 \\
3,500 \\
2,800 \\
2,464 \\
1,344 \\
784 \\
2,128\end{array}$ & $\begin{array}{l}- \\
- \\
-\end{array}$ & $\begin{array}{l}++ \\
++ \\
+\end{array}$ & $\begin{array}{l}\text { Not stud } \\
++ \\
+ \\
\text { Not stud } \\
- \\
+ \\
-\end{array}$ & $\begin{array}{l}\text { microscopic } \\
- \\
- \\
\text { microscopic } \\
+++ \\
+++ \\
-\end{array}$ & $\begin{array}{l}\text { ly } \\
- \\
\begin{array}{l}\text { ly } \\
+++ \\
+++ \\
-\end{array}\end{array}$ & $\begin{array}{l}++ \\
++t \\
++ \\
++ \\
+++\end{array}$ & $\begin{array}{l}\text { Hyaline membrane } \\
\text { Hyaline membrane }\end{array}$ \\
\hline
\end{tabular}

The second group consists of 13 babies with hyaline membrane disease. Cases 1 and 13 are of the Caesarian section syndrome. In this series the amount of membrane in the alveolar ducts varies from a little to the large quantity shown by Case 11 (Fig. 12). The variation in the quantity of membrane, and the finding of cases which have every feature of this disorder except membrane (Fig. 11), have led to the conviction that the hyaline membrane is not the cause of the disorder bearing its name but a reaction to alveolar duct type respiration. Some of the babies with this disorder showed patches of alveolar type respiration; the patches lack membrane and are apt to be emphysematous (Fig. 13). Ballooning of alveolar ducts is not emphysema and is one of the causes of interstitial emphysema (Fig. 23).

The third group consists of four babies showing emphysema. Case 3 (Fig. 14) is a severe example which might be expected to progress to interstitial emphysema. Case 1 is a mild case in a baby dying at
3 hours; this may mean that the laryngeal mechanism is not as potent as a ball valve of mucus below the vocal folds (Fig. 1); against this is the fact that the next group contains a baby also aged 3 hours which had progressed to pneumothorax.

The fourth group is made up of seven babies with interstitial emphysema and pneumothorax falling into two groups, one a complication of emphysema (alveolar type respiration), the other of ballooned alveolar ducts in membrane disease (alveolar duct type respiration). The interstitial emphysema and pneumothorax compress the emphysematous alveoli, hence the emphysema appears less dramatic than that shown in Fig. 14. Figures 15, 16, 17, 18, and 19 show typical lesions of the emphysematous form. When three of these babies had been found to have laryngeal ulceration it was decided to examine the larynx of two similar babies whose lungs had been placed in museum jars in 1957 and 1958. The second of these died after three hours; the lungs are shown 


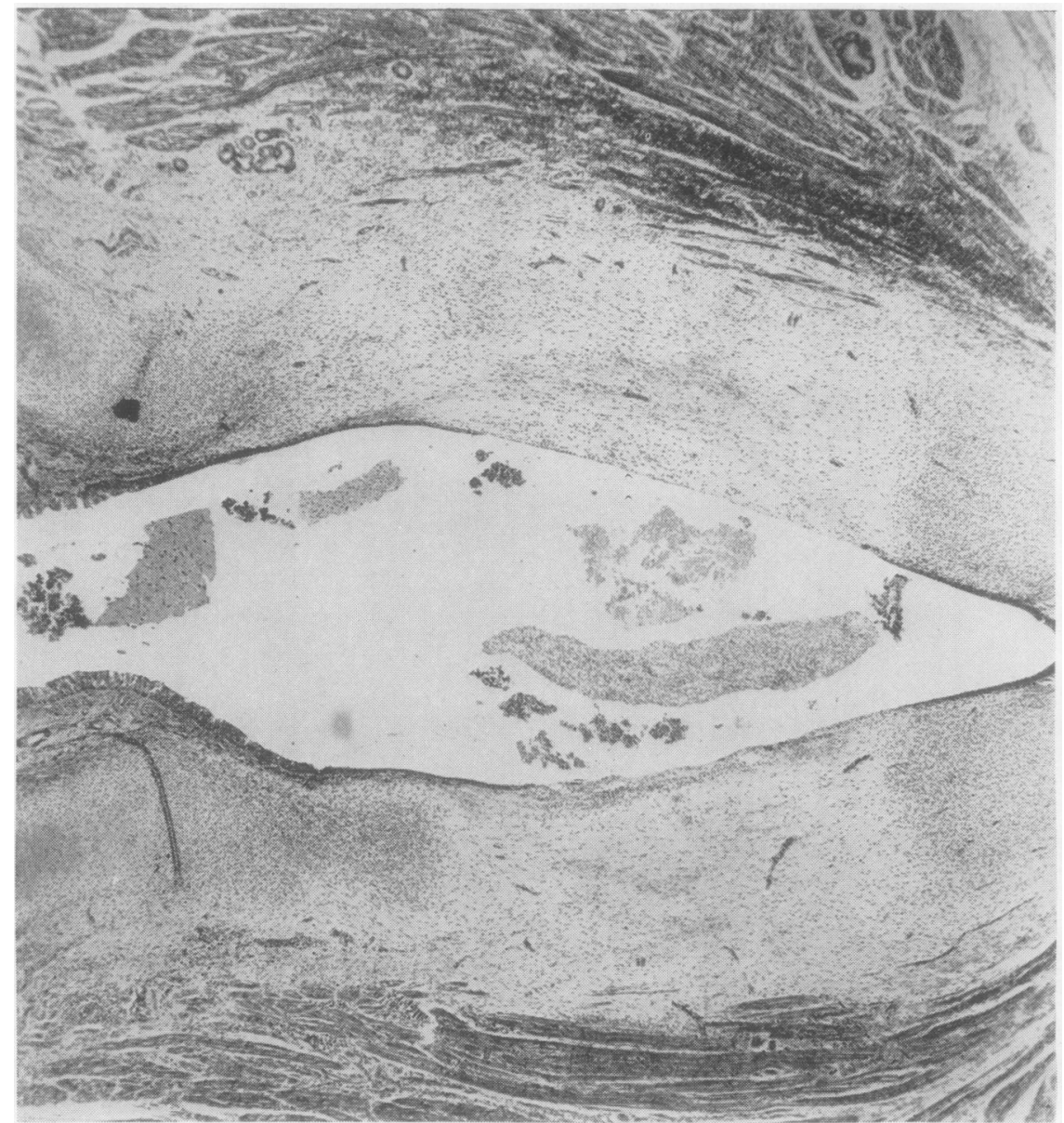

FIG. 10. Ulceration of both vocal folds in a baby dying at the age of 28 hours from broncho- $\vec{\circ}$ pneumonia. The inflammatory exudate is just developing.

Large haemorrhages of $\overrightarrow{\overline{0}}$ asphyxial type are present in the anterior part of thyroarytenoid muscle and nearby part of the vocal fold. There is no evidence that the ulcerated vocal $\rightarrow$ folds in babies follow haemorrhages, as 'singer's nodes' do in later life. The comparison with singer's nodes is by location only as there is clearly no epithelial covering to the lesion in the baby. $\times 30$.

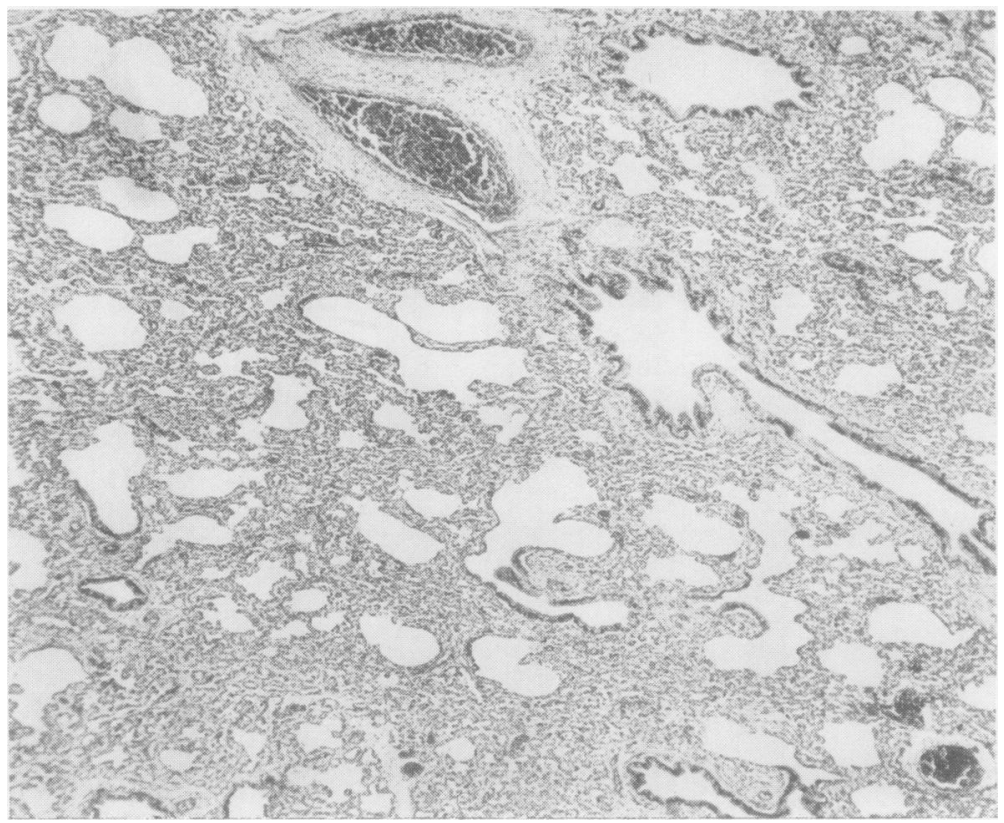

FIG. 11. Lungs of baby whose vocal folds are shown in Figure 12. I Bronchopneumonic consolidation is present. Alveolar ducts are ballooned. There is no hyaline membrane or oedema nor any emphysema except at the anterior margins of the lungs. $A$ case of 'hyaline membrane without membrane'. $\times 20$. 
FIG. 12. Male infant aged 47 hours. Abundant hyaline membrane in alveolar ducts. Oedema andsome bronchopneumonia present. Emphysema cannot occur in parts with alveolar duct membrane. $\times 120$.

FIG. 13 Same case as Figure 12. The parts of the lungs which did not have membrane in the alveolar ducts were emphysematous.

$\times 120$.

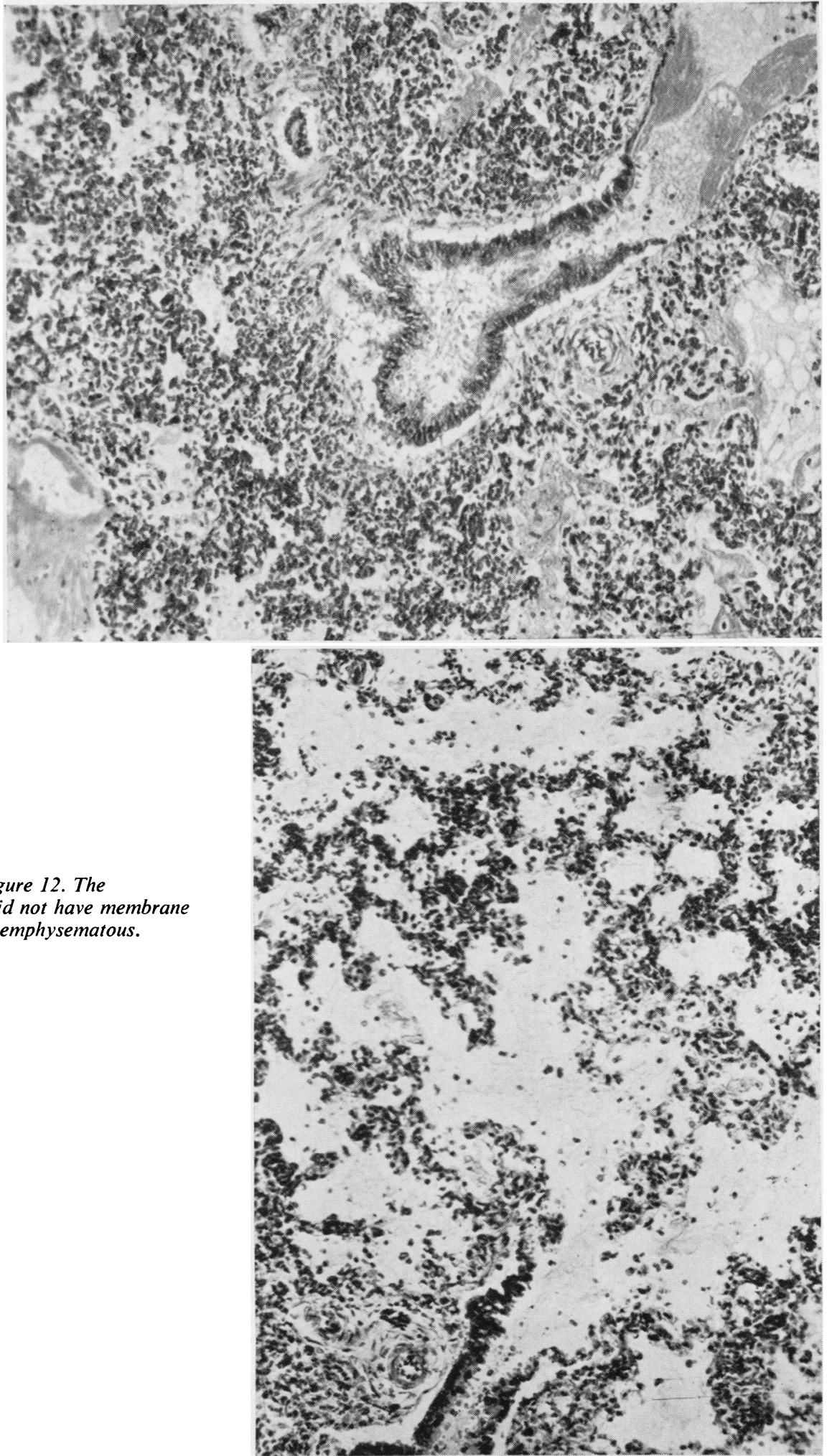




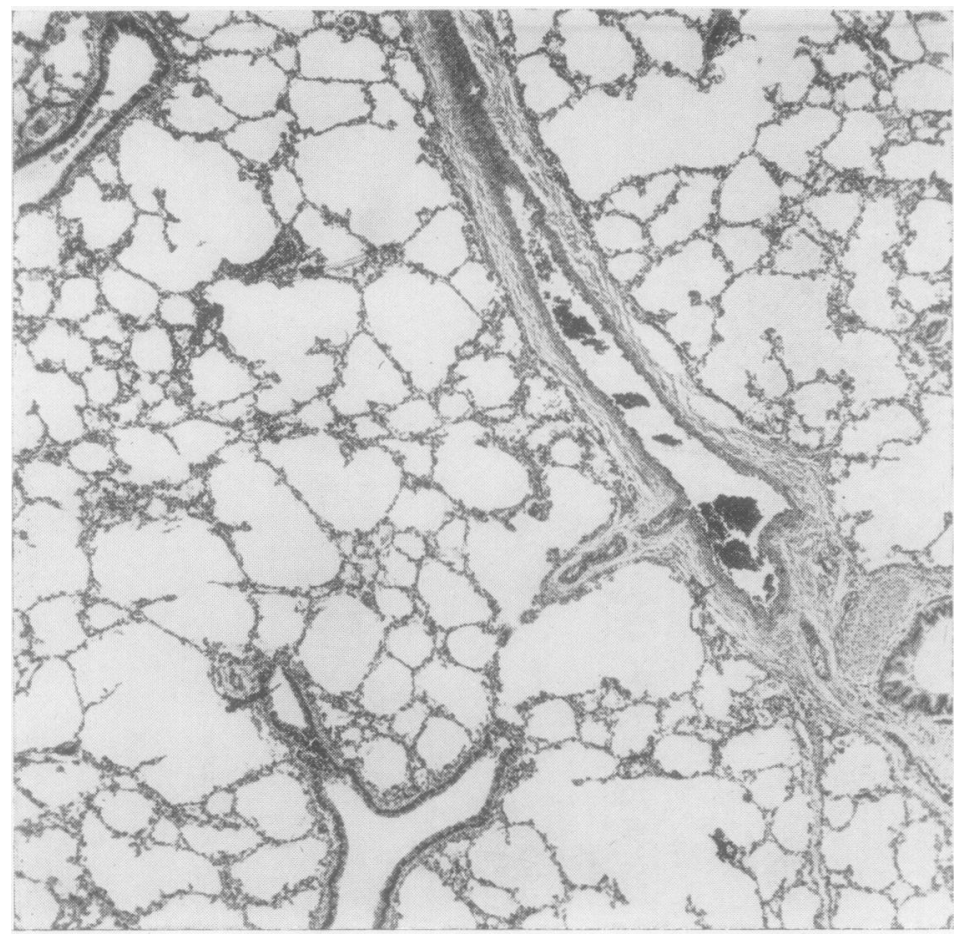

FIG. 14

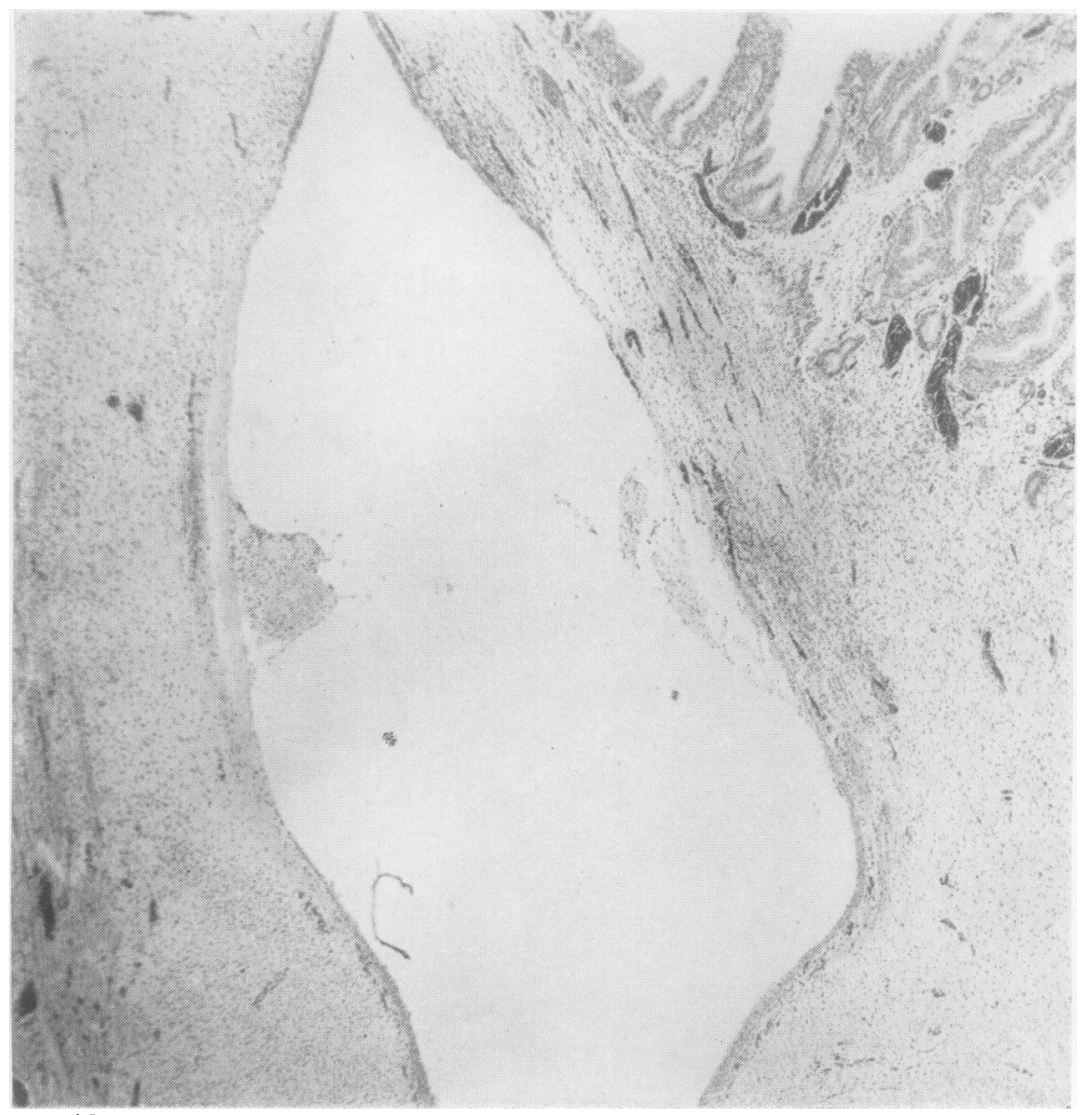

FIG. 14. Severe obstructive emphysema in the lungs of a male aged 3 days. $\times 20$.

FIG. 15. Vocal folds of a baby dying at the age of 6 hours from interstitial emphysema and pneumothorax. The exudate on the ulcerated folds resembles 'screamer's nodes'; unlike the latter it lacks an epithelial covering and is not primarily haemorrhagic. The section is at a higher level on the right than on the left, showing extension of the ulceration to the ventricular band. Note the saccule of the ventricle near the anterior part of the right side. $\times 30$.

FIG. 16. Interstitial emphysema in lung of baby whose laryngeal lesion is illustrated in Fig. 15. $\times 3$. 


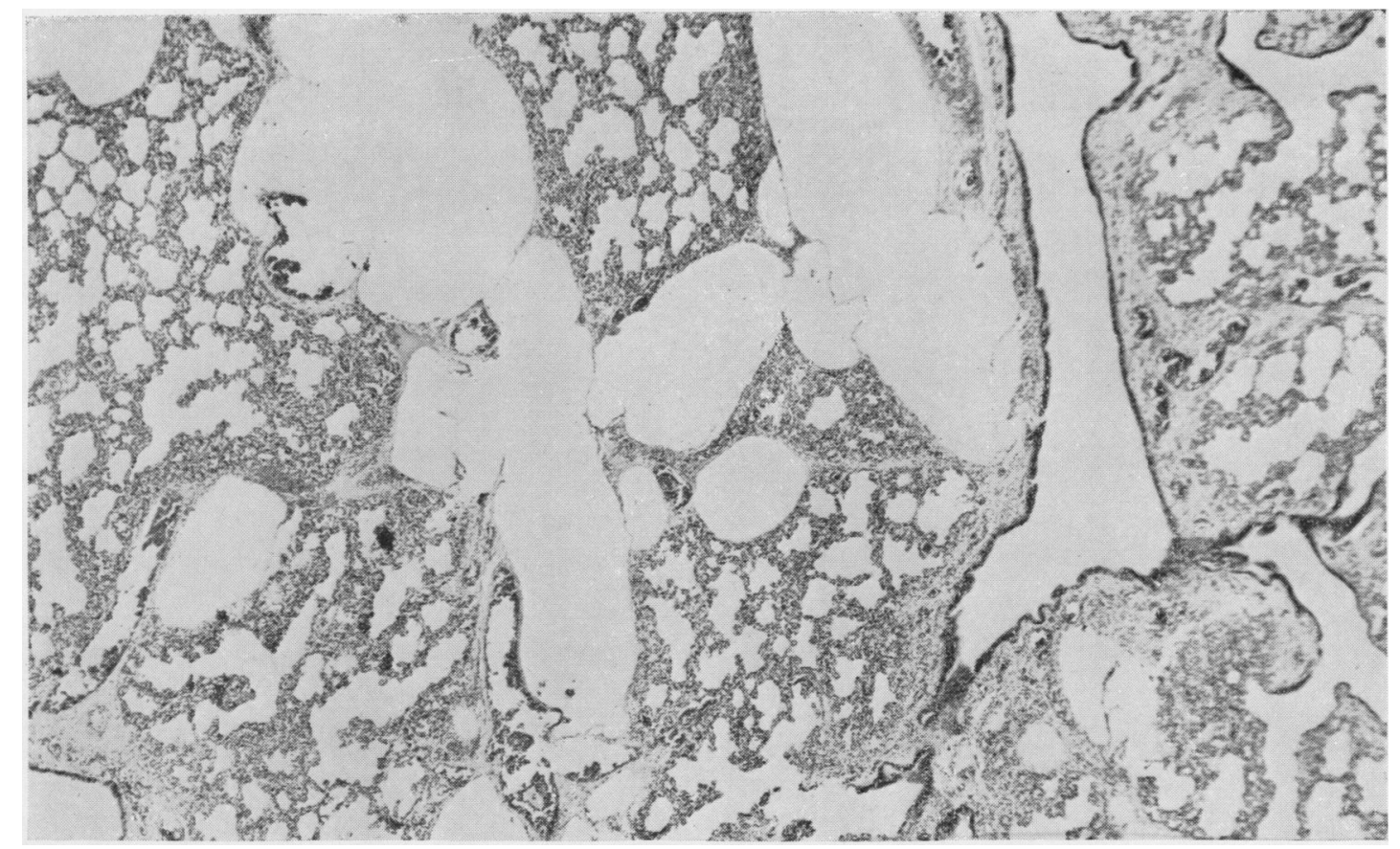

FIG. 17. Higher magnification of the lungs illustrated in Figure 16. Obstructive emphysema and interstitial emphysema are both clear. $\times 20$.

FIG. 18. Larynx of baby who died at the age of 52 hours from interstitial emphysema and pneumothorax. Although the whole of the rima glottidis will close when the vocal folds are acting as an inlet valve the ulceration is characteristically at the junction of the anterior and middle thirds. The sphincteric muscle, which alone forms the most primitive larynx, is well shown; it is formed by the thyroarytenoid, cricoarytenoid, and interarytenoid muscles. $\times 7$.

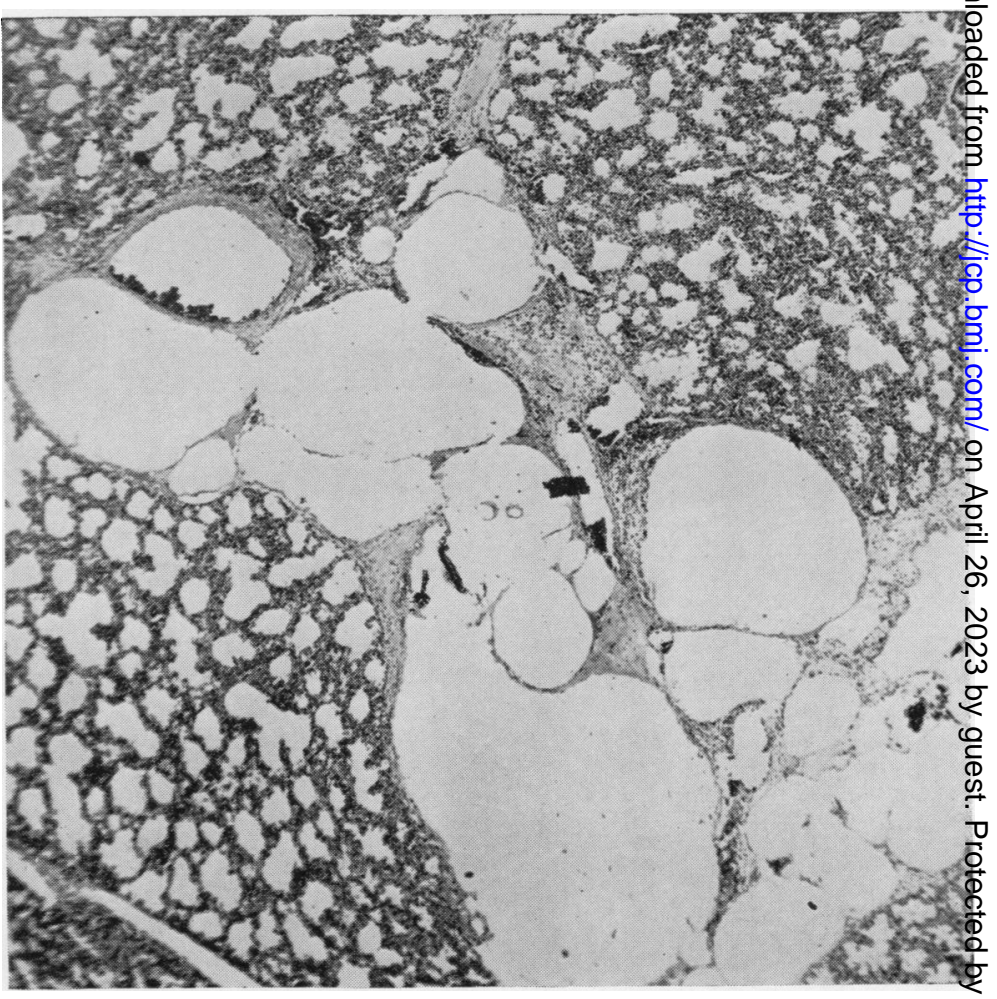

FIG. 19. Obstructive emphysema and interstitial emphysema in the lungs o̊ the baby whose vocal folds are shown in Figure 18. $\times 20$. 


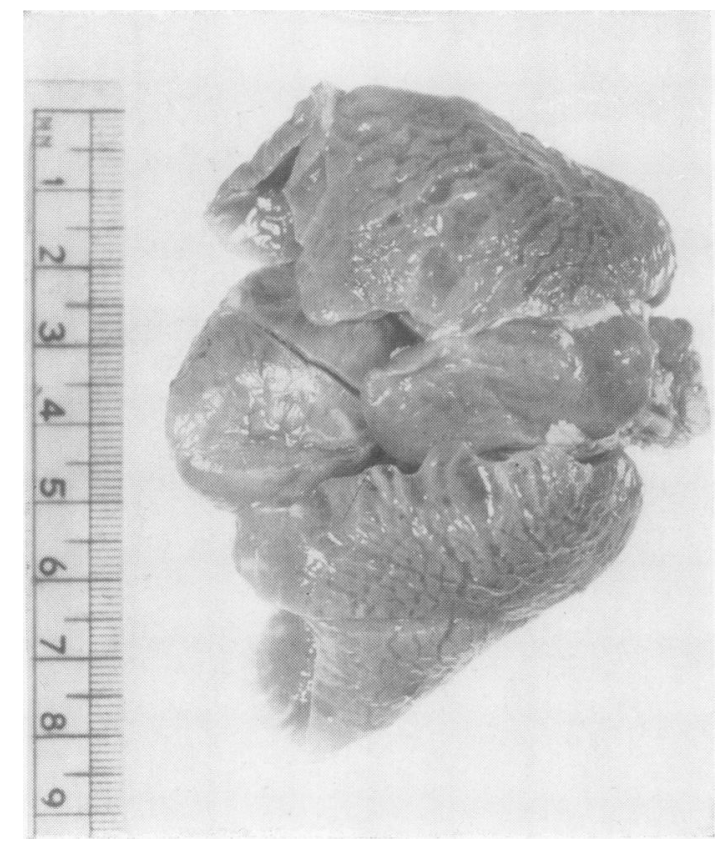

FIG. 20. Lungs of the baby whose vocal folds are illustrated in Figure 21. These lungs with the larynx were mounted in a museum jar in 1957. in Fig. 20 and the ulcerated vocal folds in Fig. 21. Figure 22 shows much more advanced inflammatory lesions in the vocal folds of the first baby who lived 10 hours longer. Hence the five most dramatic examples of interstitial emphysema and pneumothorax were complications of obstructive emphysema consequent on laryngeal spasm and ulceration. These five babies all weighed over $2,000 \mathrm{~g}$. The two much smaller babies, Cases 5 and 6 in this group, have equal striking interstitial emphysema but much less emphysema of the mediastinum and pneumothorax (Fig. 23). Both of these small babies had the characteristic ulceration of the vocal folds and a typical hyaline membrane. Excessive ballooning in alveolar duct type respiration can thus produce interstitial emrhysema and pneumothorax also. The girl (Case 4) was treated with mouth-to-mouth artificial respiration; at that time this appeared an adequate explanation for the findings but this is the only baby so treated. Mouth-to-mouth resuscitation will raise bronchial pressure during inspiration and lower it during expiration; it is thus the opposite of normal laryngeal function, and so must be dangerous in most examples of the pulmonary syndrome of the newborn.

Paediatricians are now familiar with these cases of pneumothorax. Case 7 in this group was diagnosed

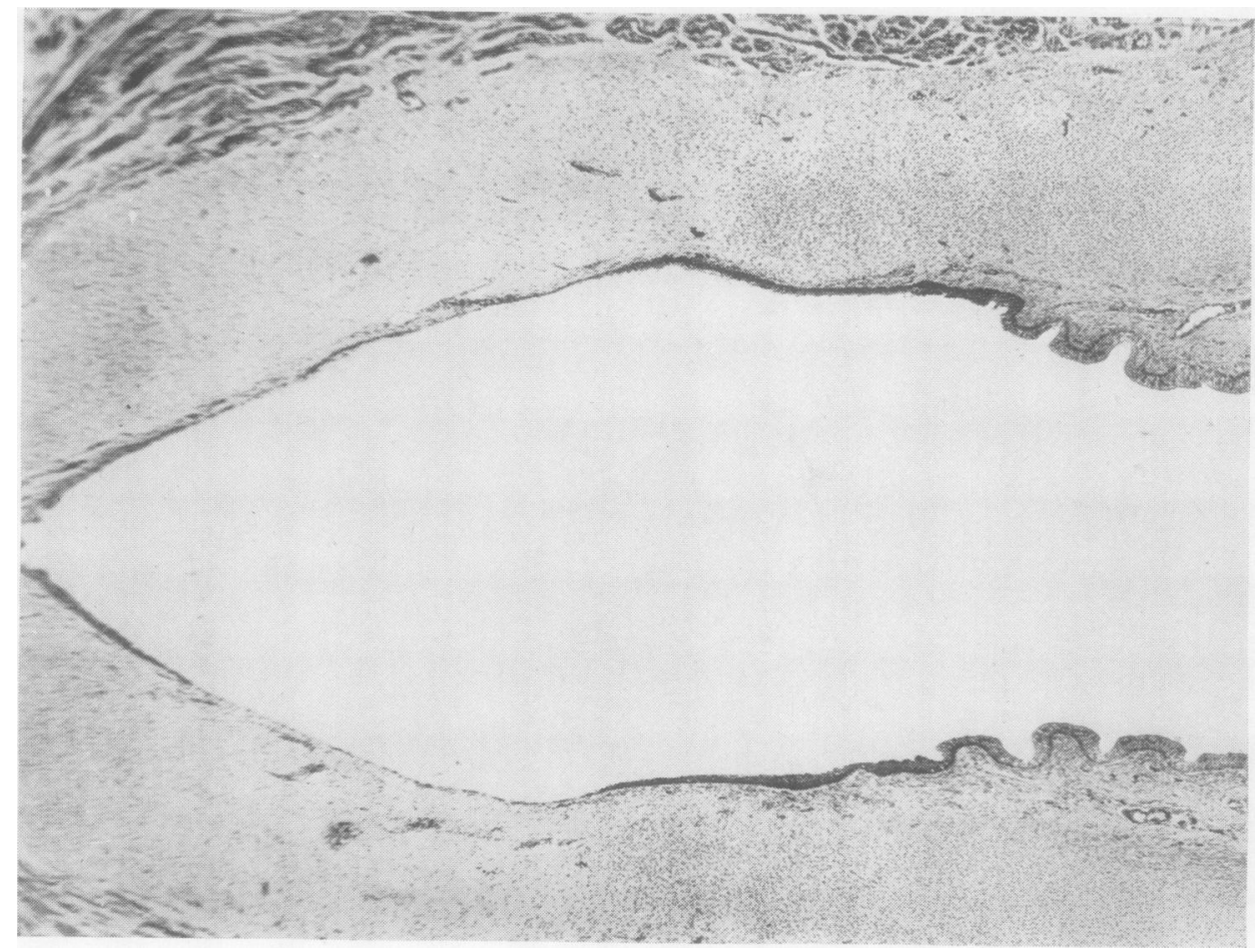

FIG. 21

Ulceration of both vocal folds of a baby dying at the age of 3 hours from interstitial emphysema and pneumothorax. Pressure atrophy of the epithelium is shown at the edges of the ulcers. The inflammatory exudate has not had time to develop to any extent. $\times 30$. 

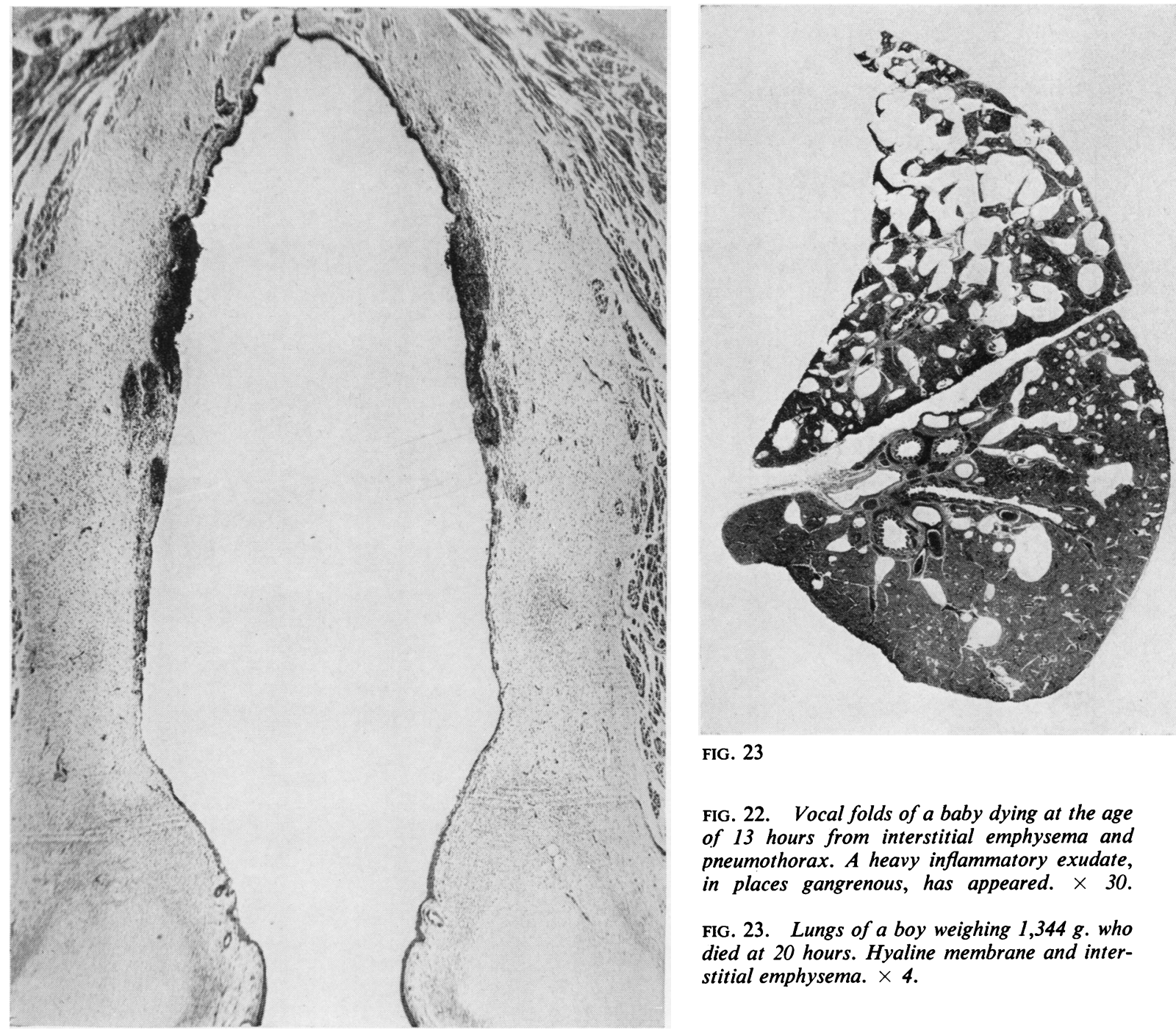

FIG. 23

FIG. 22. Vocal folds of a baby dying at the age of 13 hours from interstitial emphysema and pneumothorax. A heavy inflammatory exudate, in places gangrenous, has appeared. $\times 30$.

FIG. 23. Lungs of a boy weighing 1,344 g. who died at 20 hours. Hyaline membrane and interstitial emphysema. $\times 4$.

FIG. 22

correctly during life, and air was drawn from the left pleural cavity by a fine catheter passed through an intercostal space. This treatment appears logical until it is seen that it only affects the end of the condition instead of the beginning. Some air is allowed to pass through the vocal folds but little or none is allowed to make its way back past the ventricular bands whose shape and efficiency is similar to that of the aortic cusps. In this problem it would seem that the insertion of a small Magill tube is the method of choice (Reilly and Melville, 1962) and not tracheostomy which would be too severe on these bad-risk cases. Such a tube may prove to be the best form of artificial larynx, for it will gently assist inspiration and oppose expiration. The tube will lie posteriorly in the interarytenoid space (Fig. 18) where it may do some harm but will not aggravate the pressure ulcers on the vocal fold and ventricular bands (Figs. 7 and 8). This disorder in the newborn is not to be confused with acute tracheobronchitis and bronchiolitis in later life, e.g., that seen in epidemics of influenza. Asphyxia developing in these primarily infective cases may be treated by tracheostomy (Negus, 1952).

\section{PULMONARY SYNDROME OF THE NEWBORN}

Bound, Butler, and Spector (1956) used the term 
'pulmonary syndrome of the newborn' to cover the group of lung lesions which so often cause death in newborn babies most of which are otherwise normal. The pulmonary syndrome can be understood if it is regarded as one or more processes which are related to each other; also that although some lungs show only alveolar type, or alveolar duct type respiration, both types may be present in the same baby. The five main causes of the pulmonary syndrome of the newborn are: 1 Inhaled substances, especially squames and mucus (obstructive atelectasis and obstructive emphysema); 2 effects of laryngeal spasm in alveolar type respiration (obstructive emphysema, interstitial emphysema, pneumothorax, and surgical emphysema of the mediastinum); 3 effects of laryngeal dysfunction in alveolar duct type respiration (ballooning of alveolar ducts, hyaline membrane formation, interstitial emphysema, and pneumothorax); 4 secondary lesions in the lungs (oedema, asphyxial haemorrhages, massive haemorrhage, and bronchopneumonia); 5 secondary lesions elsewhere (serous cavity effusions, especially peritoneal, retroperitoneal oedema, posterior mediastinal oedema, and haemorrhages, especially cerebral).

In the third group 'laryngeal dysfunction' is the term employed instead of laryngeal spasm. It was at first concluded that alveolar duct type respiration was a consequence of laryngeal failure (paralysis or failure to close for other reasons). The regularity with which laryngeal lesions are found in this group indicates that it too may be a consequence of laryngeal spasm, the difference between the second and third groups being the developmental state of the lungs and possibly later development of laryngeal spasm in the second group after a period of normal laryngeal function. It is to be noted that the bronchial and bronchiolar musculatures are synchronized with the larynx and all should be considered one functional unit; probably the larynx is more important at birth and the bronchial musculature later on. Pending direct observations by laryngoscopy soon after birth it should be concluded that alveolar duct type respiration in a baby mature enough to have alveolar type respiration is a consequence of laryngeal immobility; whether the immobility is in abduction (paralysis) or adduction (spasm) may make little difference to the lungs. A larynx which fails at birth may develop normal function or go into spasm; nothing but normal function early on is of value. The likely cause of laryngeal spasm is some substance other than air passing, or attempting to pass, the larynx, especially at the level of the aryepiglottic folds. A larynx which functions normally at birth may go into spasm later.

Secondary lesions may modify the primary

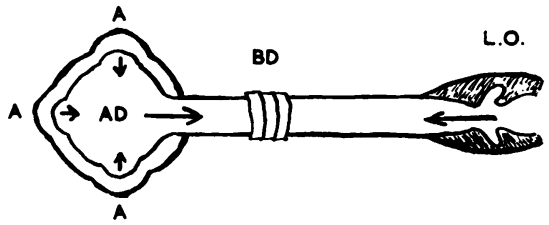

BEGINNING OF INSPIRATION

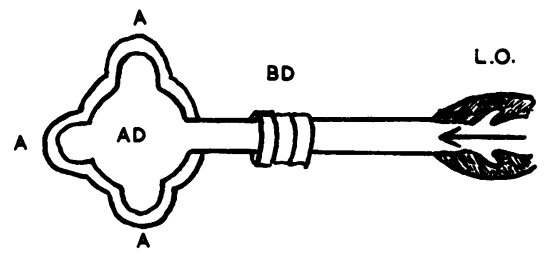

END OF INSPIRATION
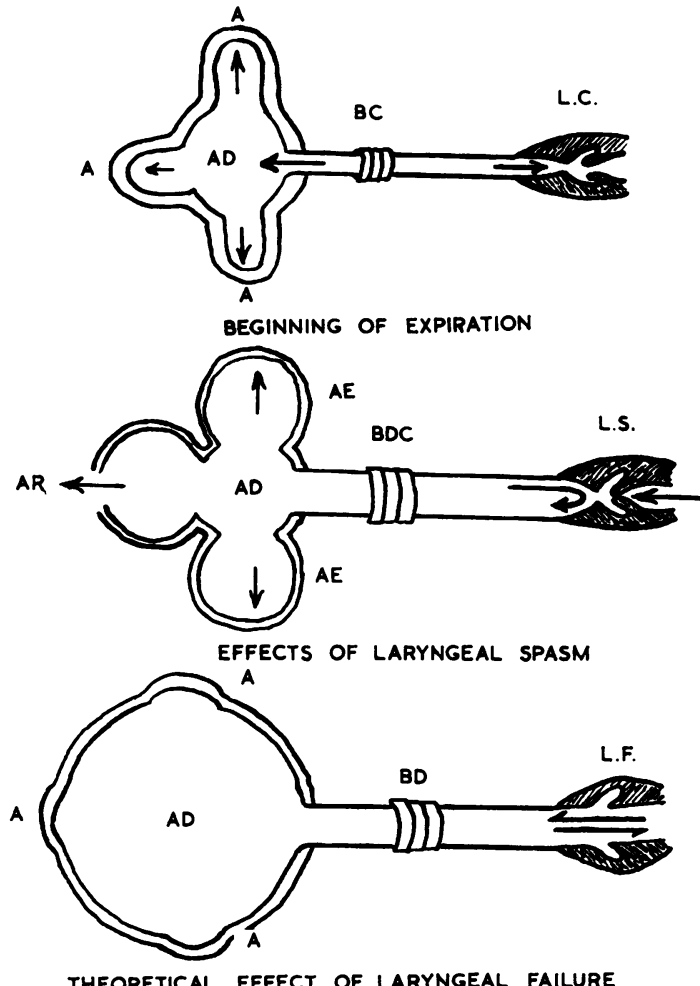

THEORETICAL EFFECT OF LARYNGEAL FAILURE

FIG. 24. $\mathrm{A}=$ alveolus. $\mathrm{AE}=$ emphysematous alveolus. $\frac{1}{\frac{1}{6}}$ $\mathrm{AR}=$ ruptured emphysematous alveolus. $\mathrm{AD}=$ alveolar duct $. \mathrm{BD}=$ bronchus dilated. $\mathrm{BC}=$ bronchus contracted. $\mathrm{BDC}=$ bronchus dilated or contracted. $\mathrm{LO}=$ larynx open. LC = larynx contracted. $\mathrm{LS}=$ larynx in spasm. LF = laryngeal failure. Arrows indicate direction of air $\stackrel{\bigcirc}{\square}$ flow. Diagrammatic representation of respiratory move- $\mathbb{\perp}$ ments (modified from Negus, 1929). 
appearances. Oedema and haemorrhage originate in alveoli and can cause the alveoli to expand and so reduce the amount of ballooning of the alveolar ducts; haemorrhage can displace membrane from alveolar ducts into bronchioles. Emphysema developing after membrane is formed can displace it into alveoli, but this is uncommon.

It is now 47 years since Chevalier Jackson (1915) noted the importance of laryngeal disorders in the newborn. Jackson and Jackson (1942) thought that the laryngeal lesions were palsies due to difficult labour, a conclusion not supported by this series. However, with the modifications indicated, there is no doubt that they were correct when they wrote 'direct laryngoscopic examination is indicated in every case of a newborn baby who fails to start respiration promptly or whose colour is not good. In some instances the cause of the cyanosis will be found in the form of an accumulation of secretions in the laryngopharynx, larynx, or trachea; in other cases a pulmonary atelectasis due to obstruction will be found; in still other instances this condition of bilateral laryngeal paralysis will be discovered as the sole factor in the impending asphyxia'.

\section{CAESARIAN SECTION SYNDROME}

This series includes two examples of the Caesarian section syndrome. Enough cases have been seen in the past to justify the conclusion that this condition is 'hyaline membrane disease', a term which should be changed to 'alveolar duct type respiration'. The 'Caesarian section syndrome' may be seen in premature babies who are predisposed to alveolar duct type respiration or in full-term babies in which it is otherwise rare and can have only a few causes. Laryngeal failure may be a consequence of the anaesthetic administered to the mother and laryngeal spasm of the rapid delivery and clamping of the cord and the presence of substances other than air in the region of the larynx.

It should be possible to abolish the Caesarian section syndrome by discovering the factors responsible for laryngeal dysfunction in a baby in which normal alveolar type respiration might be expected and preventing their emergence. If the baby delivered by Caesarian section is premature it may require immediate treatment with an artificial larynx after the airways have been cleared. The best form of artificial larynx could well be the passage of a gentle stream of air into the trachea through a Magill tube which will lie in the posterior (interarytenoid) part of the larynx. This treatment may only be required for 10 minutes or so but it must be long enough for alveolar expansion to prevent ballooning of the alveolar ducts.

\section{LUNG LESIONS WITHOUT, AND WITH, ULCERATION OF THE LARYNX}

A variety of lung lesions, especially those dependent on congenital malformations and bronchopneumonia, may occur without laryngeal ulceration although laryngeal ulceration in the newborn may occasionally be secondary to infection.

As our technical skill in the histological examination of the larynx has increased it has become clear that ulceration of the vocal folds and ventricular bands is the rule in the pulmonary syndrome of the newborn. It was first found in babies with emphysema and the correlation here is simple. It was thought then that it would not be found in 'hyaline membrane disease', but it is the rule in this disorder too. Hence laryngeal dysfunction and ulceration are the most important of the causes of the pulmonary syndrome of the newborn.

We are grateful to Sir Victor Negus for his criticism of this paper and to Mrs. M. S. Costello and Mrs. V. M. Keen for their help in cutting the sections. We are also grateful to the Clinical Research Committee of the Sheffield Regional Hospital Board for financial assistance.

The photographs were taken by Mr. J. S. Fayers, clinical photographer to the Derbyshire Royal Infirmary. Finally we are indebted to the obstetricians, paediatricians, and midwives who supplied full case notes.

\section{REFERENCES}

Bound, J. P., Butler, N. R., and Spector, W. G. (1956). Brit. med. J., 2,1191 and 1260 .

Cavanagh, Florence (1955). J. Laryng., 69, 399.

Jackson, C. (1915). Peroral Endoscopy and Laryngeal Surgery. Laryngoscope Co., St. Louis.

- and Jackson, C. L. (1937). The Larynx and Its Diseases. Saunders, Philadelphia.

(1942). Diseases and Injuries of the Larynx. Macmillan, New York.

- -1 (1945). Diseases of the Nose, Throat, and Ear. Saunders, Philadelphia and London.

McLaren, H. C. (1961). Personal communication.

Negus, V. E. (1929). The Mechanism of the Larynx. Heinemann, London.

(1949). The Comparative Anatomy and Physiology of the Larynx. Heinemann, London.

(1952). Thorax, 7, 36.

(1961). Brit. med. J., 2, 723.

Osborn, G. R. (1953). In Modern Trends in Forensic Medicine, ed. Keith Simpson, pp. 33-52. Butterworth, London.

(1958). Proc. roy. Soc. Med., 51, 840.

Reilly, R. J. R., and Melville, H. A. H. (1962). Brit. med. J., 1, 91. 